\title{
An Analysis of Pedagogic Research IN PHYSIOTHERAPY EDUCATION
}

\begin{abstract}
Purpose: The focus of this retrospective review paper is to explore and analyse pedagogic research development in physiotherapy education in South Africa.

Methods: A content analysis of publications by educators in the SA Journal of Physiotherapy between 1989 and 2003 was conducted to identify and classify the pedagogic articles. Further analysis of physiotherapy educa-

Mothabeng DJ, BSc. Physio, MPhysT, DT ${ }^{1}$

${ }^{1}$ Lecturer, Physiotherapy Department, University of Pretoria. tion articles was performed to determine the primary foci of the education research, using a three-dimensional pedagogic outcomes research framework.

Data analysis: Descriptive statistics in terms of frequencies, means and percentages was used for the analysis.

Results: The results revealed that most of the educators' articles focused on clinical practice. Only $23 \%$ of the articles were about education and the majority of those were on clinical education (72\%), with few articles on curriculum issues and teaching methods.

Conclusion: The research focus of South African Physiotherapy educators is more on the clinical practice, and not on education. The importance of linking research, clinical practice and education cannot be overemphasized, hence the need to develop research in education.
\end{abstract}

KEY WORDS: PEDAGOGIC RESEARCH, PHYSIOTHERAPY, EDUCATION.

\section{INTRODUCTION}

\section{Background}

This study was conducted during 2004, a year marking an important milestone, the end of the first decade of democracy in South Africa. That same year, the physiotherapy profession celebrated 80 years of having a professional organization. It was thus timely to reflect on developments in certain aspects of the profession.

The South African government has since the elections of 1994, embarked on an urgent programme of restructuring its education system on principles of equity, human rights, democracy and sustainable development to redress the inequalities of our past. Numerous changes including higher education reforms were implemented. Restructuring of higher education is about a higher

CORRESPONDENCE TO: Mrs DJ Mothabeng Box 58213

Karenpark, 0118

Tel: (012) 549-4334 (home)

Tel: (012) 354-1200 (work)

Fax: (012) 354-1226 (fax)

E-mail: joyce.mothabeng@up.ac.za education system that will contribute to the advancement of all forms of knowledge and scholarship, the overall goal being to build a critical mass of researchers and educators. (White Paper: 1.14). The focus of this paper is on physiotherapy education in South Africa, with specific reference to pedagogic research (i.e. research into teaching and learning) in physiotherapy education.

Physiotherapy education is part of the mainstream higher education sector, which has been undergoing changes within a variety of areas in the past decade. The move of Physiotherapy education to universities with their ethos for research and enquiry challenges the profession to develop as a strong research based discipline and to participate in pedagogic and academic debate (Mercer et al 2002).

Physiotherapy educators are in the business of education and should research their practice to ensure quality and acceptable standards. Unfortunately, a pedagogic background or knowledge is not a prerequisite for teaching physiotherapy in South Africa, and most of the lecturers teach because they have a special interest in or are good with particular aspects physiotherapy. Whether their teaching methods and approaches are relevant and appropriate or effective is rarely questioned. With the recent developments in evidence based medical education, health care educators are expected to base their teaching practice on scientific evidence.

Evidence based education (EBE) is a fairly new concept, sharing similar principles with "evidence-based medicine and evidence based practice". EBE is about using the best available evidence to guide teaching practice (Chipchase et al 2004). It means that educators must not only teach what has been proven to be effective, but must use evidencebased methods to teach as well. The extent to which physiotherapy educators do the later has not been established in the literature; and is the main question of this study. This shortcoming in the physiotherapy literature is not only seen in South Africa but globally too.

\section{Problem statement}

The physiotherapy profession has a historical tradition of practical and experience based knowledge. Although there has been an increase in research based knowledge in the past few decades, the challenges facing the profession are 
such that new ways of promoting research and further developing research within the profession are imperative (Dahlgren 1999). There is currently no evidence on Physiotherapy education to suggest that educators use evidence to select teaching methods or to guide their teaching content. In their exploratory study on lecturer practitioners in physiotherapy, Hargreaves and Hewison (2002) emphasized the need for more research into the tripartite role of the physiotherapy educator namely research, practice and education.

The results of a pilot study to test the methodology for this study revealed that only eleven out of the twenty-five articles published in the South African Journal of Physiotherapy in the year 2002 were from physiotherapy educators (Mothabeng 2003). Only three of the eleven articles were on physiotherapy education. Considering that there are eight institutions training physiotherapists in the country, one would have expected a higher number of publications in the local journal. This led one to wonder why physiotherapy educators were not aggressively involved in publishing research, especially pedagogic research.

The lack of pedagogic research in physiotherapy has been a topic of debate and discussion in international literature (Sparkes 2002). Physiotherapy educators worldwide publish a lot of clinical research, and not enough if any about pedagogic research. According to Sparkes (2002), the reason behind this trend is because physiotherapy educators have not yet acknowledged the fact that their primary occupation is teaching, and not clinical practice. This problem is not peculiar to physiotherapy educators only, but is common to most higher education practitioners (Healy 2000). There is therefore a need to explore this problem and come up with strategies to promote pedagogic research.

\section{Research questions}

The question to be answered in this study was: What is the status of pedagogic research in the South African physiotherapy literature?

\section{AIM OF THE STUDY}

The aim of the study was to analyze pedagogic research trends/patterns in the
South African Journal of physiotherapy (SAJ Physiother) over a twenty-year period, and the implications thereof to physiotherapy education.

\section{METHODOLOGY}

Documentary research, which refers to the analysis of written documents using content analysis, was employed in this study. Content analysis is defined as a "...documentary method that aims at a qualitative analysis of the context of texts, pictures, films and other forms of verbal, visual or written communication ", (Sarantakos 2000).

\section{Population and sample}

Articles published in the sixty (60) journals published in the South African Journal of Physiotherapy between February 1989 and November 2003 constituted the population from which pedagogic articles were sampled for analysis. Non-data driven articles (i.e. editorials, letters, abstracts and book reviews) were excluded from the analysis.

\section{Method}

A content analysis of Physiotherapy pedagogic articles in the SA journal of Physiotherapy was conducted to determine the demographic profile of the authors and to classify the articles. The content analysis was conducted as previously described through a pilot study by Mothabeng (2003). Two reviewers who agreed on the rules for categorization, the definition of the primary participants, outcome measures, and levels of analysis were involved in the review. In cases of disagreements, a third reviewer was consulted for mediation.

\section{Authorship}

Authorship classification considered the race and gender of the first author according to the method by Ruth (2002) in her study on perceptions of South African academics concerning workload. A race-gender combination was used for coding South African physiotherapy authors in this study (for example a white female author is code WF). Other authors e.g. doctors or nurses were classified non-physiotherapist and coded NPT. The abbreviations SA or NSA were used to indicate whether the first author is South African or not.

\section{Topic category}

Three main categories of topics namely clinical practice, education, and research, representing the main professional practice areas of physiotherapy educators were used. All other topics that did not fall into any of the three were categorised 'other' and specified.

\section{Pedagogic Research outcomes analysis} It was the intension of the study to further analyze the pedagogic research articles according to a three-dimensional framework for analyzing medical education research articles as described by Prytowsky and Bordage (2001). The framework looks at the primary participant (i.e. trainee, faculty, provider or patient), outcome (i.e. performance, satisfaction, professionalism and cost for trainees, faculty, and provider, and clinical outcomes, satisfaction, quality of life or functional state, and cost), and level of analysis (i.e. geographic area, system, institution and individuals). The pedagogic research articles found in this study were too few and a lot of them were not empirical studies so they could not be analyzed using the framework.

\section{Data analysis}

The articles were divided into five-year periods for analysis purposes, in keeping with previous physiotherapy research trend studies (Robertson 1995, Mothabeng 2000). This division also allowed for an evaluation of changes in research trends and the build-up and development of knowledge through research (Robertson 1995).

The first five-year period represent the 'pre-democracy' era from 1989 to 1993. The reason for including this period was to obtain a picture of the research within the profession before national health and education reforms were introduced, in order to compare with the post democracy period. The second period was the immediate postdemocracy era from 1994 to 1998 . The last period marked the end of the first decade of democracy from 1999 to 2003.

The data was captured on a spreadsheet. The data was quantified for analysis purposes. Descriptive statistics in terms of frequencies, means and percentages were used for the analysis. 


\section{RESULTS}

A total of 224 articles were published during the period under review (table 1). One hundred and forty-three $(63,8 \%)$ were form academics and only twenty one of those $(9,4 \%)$ were pedagogic articles.

\section{Authorship}

The majority of authors of articles were white females $(52,4 \%)$. The trend remains the same in all the year periods. A slight change in the gender and race of pedagogic article authors is noticed in the 1999 to 2004 period. (Figure 1)

\section{Articles and topics}

Figure 2 shows the number of pedagogic articles per topic category and how these changed over the period under investigation. Between 1989 and 1993, there were only 2 articles $(9,5 \%)$ that were related to education. Both of them were perspectives on the physiotherapy curriculum. A slight change is observed between 1994 and 1998, with an increase to six (6) in the number of pedagogic articles (28\%). Between 1999 and 2003, the number of pedagogic articles changed even further to $14(66,7 \%)$.

Most of the articles were on clinical education, and looked at needs of educators, models of clinical education and student experiences in the clinical education. Others were author perspectives on curriculum issues. There were no articles on teaching and learning methods and/or styles.

\section{DISCUSSION}

There is a vast amount of literature on research and/or publications in physiotherapy generally, but very little on physiotherapy education. Most of the literature on Physiotherapy publications has looked at the issues descriptively through publication trends (Robertson 1995, Klaasen et al 2001), and not analytically. What is crucial should not just be what trends are observed, but the meaning and implication of the trends to the profession.

The acronym 'TIPS' (Trends, Issues, Problems and Strategies) will be used to guide this discussion in probing the meaning and implications of observations made in this study and lead to the conclusion.

Táble 1: Population and sample of participating articles.

\begin{tabular}{|l|c|}
\hline Population $\mathbf{( n = 2 2 4 )}$ & Sample $(\mathbf{n}=\mathbf{2 1})$ \\
\hline $\mathbf{2 2 4}$ articles were published & 31 articles on educcation \\
& 5 Student \\
143 by academics & $3 \mathrm{~N} \mathrm{SA}$ \\
$->50 \%$ & $2 \mathrm{NPT}$ \\
& 0 nly $\mathbf{2 1}$ analyzed \\
& $=9,4 \%$ \\
&
\end{tabular}

Figure 1: Changes in author demographics over the three five-year periods.

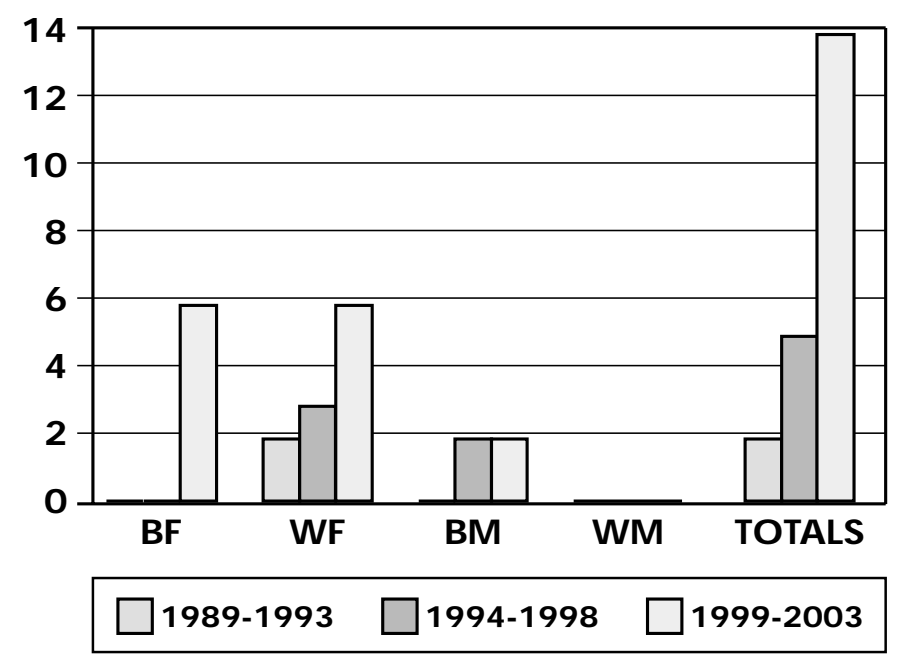

Figure 2: Pedagogic topics/ focus areas identified.

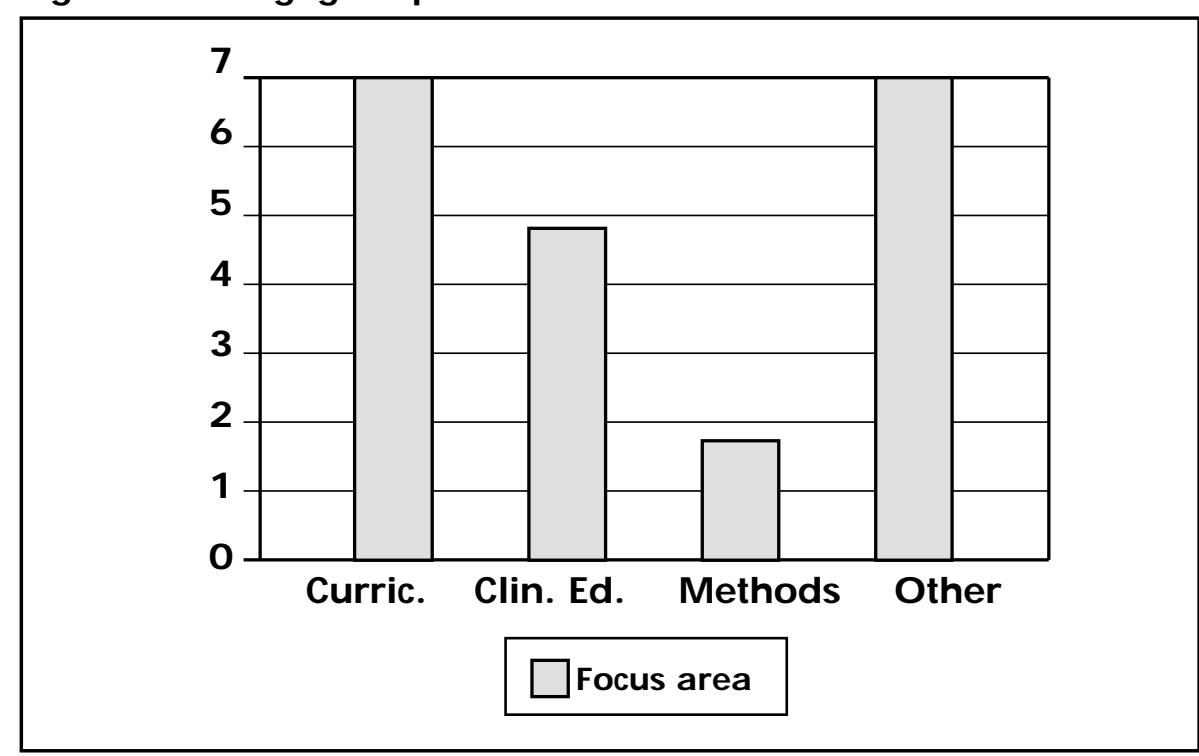

\section{Trends}

\section{Demographics}

The demographics of the publications in the South African Journal of Physiotherapy still reflect the sad reality of our unfortunate past, in keeping with previous observation by Mothabeng (2004). Article authorship is still dominated by females, the majority being white, with very few black South African authors.

The number of black female-authored articles improved from zero in the first 
two phases to six in the last phase of the study. The slight improvement in the number of black male-authored pedagogic articles (from zero to two and two) unfortunately refers to the same one black male author! An interesting finding is that there were no white maleauthored pedagogic articles. This trend is understandable, considering that the physiotherapy profession is predominantly white and female in South Africa, but is not acceptable because white male educators do exist!

The number of pedagogic articles in physiotherapy is gradually increasing, also in terms of author demographics. The observed improvement in the author demographics albeit still small, indicates a real demographic transformation in the profession.

\section{Focus areas}

The focus areas of the pedagogic articles were varied, and covered a variety of topics on clinical education, research education and the curriculum. The majority of the articles were perspectives, reviews and very little empirical research. Hence the outcomes focus was difficult to determine in terms of variables being measured. Using the topic focus however, it could be determined that the main pedagogic research issues being reported on were the curriculum, clinical education and very little on students' views, perceptions and/or satisfaction.

Although clinical education in Physiotherapy is extensively researched and numerous aspects of clinical education are looked into, the students' perception with regard to the clinical learning environment has not been taken into account in the physiotherapy literature (Mothabeng 1999). Most of the physiotherapy literature is concerned with the clinical supervisor and/or clinical supervision, which is but an aspect of clinical education (Coates 1991, Onouha 1994, Cross \& Hicks 1997, Hunt et al1998, Mbambo 1999).

Curriculum issues reported in the journal were based on review papers and author perspectives, with no empirical research conducted into teaching methods and/or approaches. Physiotherapy education involves teaching and learning by adults. It is important therefore that teaching methods used are appropriate for adults, and are based on the best evidence on the most effective ways of teaching adults. With the recent developments in evidence based medical education, health care educators are expected to base their teaching practice on scientific evidence (Bligh and Parsell 1999). Pedagogic research projects need to be planned and implemented with the aim of measuring the effectiveness of a specific strategy. "Pedagogic strategies and techniques should be implemented on the basis of evidence, not just because they are in fashion" (Eksteen, 2001).

The international literature physiotherapy education focuses on issues of the curriculum. Most of the literature recommends a Problem Based Learning (PBL) approach to teaching and learning in Physiotherapy. PBL has become the pedagogic buzzword, although no evidence exists to suggest that it is the best. The reason for the lack of evidence is the fact that designs are poorly described, making comparison between studies virtually impossible. (Eksteen 2001).

The lack of pedagogic research is not unique to physiotherapy education in South Africa only. Sparks (2002) highlighted this problem in an interpretive paper as prevalent among United Kingdom physiotherapy educators as well. Lecturers tend to fall into the trap of thinking that because they know what ultimate qualities students must possess, they can decide on the best method of making sure students achieve those qualities (Neville and French, 1991). However, teaching means more than just lecturing, explaining or demonstrating a skill or procedure (op cit.). It is important to know what students need, how they feel about our teaching methods, how they study, what their learning styles are and if those are in line with our teaching styles. Students as the main consumers of education are thus very important stakeholders who can give valuable input on the effectiveness of the education system/processes.

\section{Issues and/or Problems}

Pedagogic research is not well developed in higher education generally, and physiotherapy specifically (Healy 2000,
Sparkes 2002). These two authors suggest that the reason for this is a "conflict of interest or loyalties". They argue that because physiotherapy educators are first clinicians before they are educators, they do not acknowledge their professional shift to education. "Most educators do consider their primary allegiance to be their subject or discipline, with their teaching function being secondary" (Healy 2000).

The findings of this study, whereby over $54 \%$ of the articles in the study population were from academics and only $9,4 \%$ of the educators' articles were on pedagogic issues confirm this statement. Pedagogic research is an important aspect of the scholarship of teaching and learning, which is the hallmark of an academic (Boyle 1990). Physiotherapy educators are employed to teach and should therefore focus their main research efforts on their primary practice, which is teaching.

Two sources of external pressure are possibly responsible for the physiotherapy educators' insistence on conducting more clinical than pedagogic research.

1. According to the South African Higher Education Act, university lecturers are expected to perform three main duties namely teaching, service and research (SA Ministry of education 2003). The service component of physiotherapy educators' function is mainly in the clinical arena. It is therefore easy for educators to conduct research in the area of specialty they teach. The situation is aggravated by those educators who have an obligation to work in a hospital (i.e. Joint appointments), as they spend part of their work in the clinical arena anyway. For those educators, it is much easier to conduct clinical research.

The pressure of evidence based practice (EBP) demands that whatever educators teach to students must be based on sound evidence. A large amount of literature has shown that physiotherapy clinicians are generally reluctant to conduct research (Connoly et al 2001; Hamzat and Amusat 2002; Kamwendo 2002). Therefore lecturers have no choice but to get involved in the clinical research, in order to teach evidence-based material; and to foster a culture/spirit of EBP in the students. 
Evidence based education is however not only about teaching techniques or treatment approaches, but also about using the best evidence based method to teach (Chipchase et al 2004)! This is unfortunately what is lacking in physiotherapy education. This raises questions as to what it is then that informs our decision to choose a certain education strategy. Is it because it is the new buzzword in healthcare education like problem based learning (PBL) was at the beginning of the past decade? Is it because some psychologist or nurse educator or medical education specialist found it to work for their students? If so can we justifiably assume that it will work for physiotherapy students?

\section{CONCLUSION}

The purpose of this study was to evaluate the status of physiotherapy pedagogic research in South Africa. During the analysis of the pedagogic articles, it became evident that the PT educators are involved in research activity, but not in their primary area of practice which is education. Research is important for guiding practice, including the practice of physiotherapy education. Physiotherapy education, like other forms of professional practice, should be evidence based (Chipchase 2004). There is therefore a need for more pedagogic research development in physiotherapy.

\section{ACKNOWLEDGEMENT}

This paper was presented at the European congress on Physiotherapy Education that was held in Estoril, Portugal in November 2004; funded by the University of Pretoria. The author also thanks her colleagues in the Physiotherapy department for all their support and encouragement throughout the project.

\section{REFERENCES}

Best D 1988 Physiotherapy clinical supervision; Effectiveness and the use of models. Australian Journal of Physiotherapy 34: $209-214$.

Bligh J, Parsell G 1999 Research in medical education - finding its place. Medical education 33: $162-163$

Chipchase L, Dalton M, Williams M, Scutter S 2004. Editorial: Is education immune from evidence based scrutiny? Australian Journal of Physiotherapy (50) 133 - 135

Coates F 1991 'Clinical supervision - no! Clinical instruction - yes!' Cited in Neville S and French S : Physiotherapy 77 (5), 351 - 354.

Connoly BH, Lipinnaci NS, Bush AJ 2001 Changes in attitude and perception about research in physical therapy among professional physical therapist students and new graduates. Physical Therapy 81: 1127 - 1134

Cross V, Hicks C 1997 What do clinical educators look for in Physiotherapy students? Physiotherapy 83: 249-260.

Dunn SV, Hansford B 1997 Undergraduate nursing student's perception of their clinical learning environment. Journal of Advanced nursing 25:1299 -1306.

Eksteen CE 2001 Challenges facing Physiotherapy Education. South African Journal of Physiotherapy 57:2 - 3

Hamzat TK, Amusat NT 2002 Belief and participation of clinical physiotherapists in research. South African Journal of Physiotherapy 58 (2): 32 - 34

Harth SC, Bavanandan S, Thomas KE, Lai MY, Thong Y H 1992 The quality of student-tutor interactions in the clinical learning environment. Medical Education 26:321-326.

Healey M 2000 Developing the Scholarship of Teaching in Higher Education: a disciplebased approach. Higher Education Research and development 19:169 -189.

Hunt A, Adamson B, Higgs J \& Harns L (1998): University education and the physiotherapy professional. Physiotherapy 84:264-273.

Kamuendo K 2002 What do Swedish physiotherapists feel about research? A survey of perceptions, attitudes, intensions and engagement. Physiotherapy Research International 7:23 - 34

Klaasen LE, Grzybowski WE, Rosser WCB (2001) Trends in Physiotherapy Research and scholarly activity. Physiotherapy Canada 48: 40-41
Mbambo NP 1999 Pedagogic perspectives. Physiotherapy clinical educator's needs. South African Journal of Physiotherapy,55:16-9

Mercer SR Galvin KA Jones DG 2002 Academic freedom in physiotherapy teaching. Physiotherapy 88:303 - 306

Mothabeng DJ (1999) Students' views on the clinical learning environment. Unpublished masters thesis, Physiotherapy department, University of Pretoria, South Africa

Mothabeng DJ 2003 Research and the Physiotherapy Profession in South AfricaReflections on a pilot study. South African Journal of Physiotherapy 59: 9 - 15

Mothabeng DJ 2004 Editorial - The vision of our Scholarship. South African Journal of Physiotherapy 60: 2

Neville S, French S 1991 Clinical Education: students and teacher's views. Physiotherapy 77:351 - 354 .

Onouha RAA 1994 Effective clinical teaching behaviors from the perceptive of students, supervisors and teachers. Physiotherapy 80: 208-214

Prystowsky JB Bordage G 2001 An outcomes research perspective on medical education: the predominance of trainee assessment and satisfaction. Medical education 35: 331-336

Ruth D 2000 Perceptions concerning academic workload among South African academics. Available: www.aau.org/studyprogramme/listofresearchreports.html

Robertson JV 1995 Research and the cumulation of knowledge in Physical Therapy. Physical Therapy 75 (3) 223 - 236

Sarantakos S 2002 Social Research. 2nd ed. McMillan Education. Australia (PTY) Ltd.

SA Ministry of Education 2003 Higher education Act 101, 1997. Policies and procedures for the measurement of research output of public higher education institutions. Available at: www.education.gov.za

Sparkes VJ 2002 Profession and professionalism Part 2: Professionalism within academia. Physiotherapy 88: 481 - 492 